
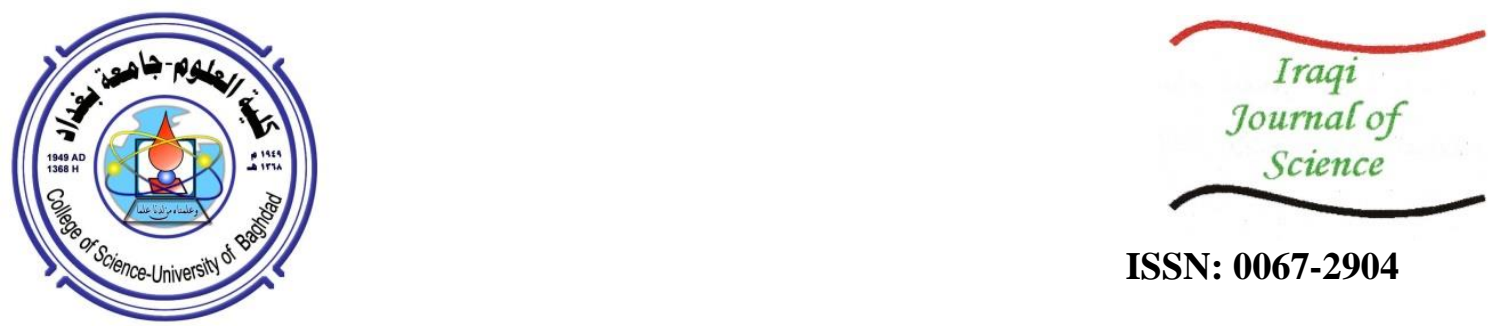

ISSN: 0067-2904

\title{
The Antimicrobial Effects of Alcoholic Leaves Extract of Salvia Officinalis Against Multidrug Resistant Pseudomonas Aeruginosa
}

\author{
Enass Ghassan Sweedan \\ Department of Biology, College of Science, University of Baghdad, Baghdad, Iraq
}

Received: 3/4/2020

Accepted: 5/7/2020

\begin{abstract}
Two isolates of Pseudomonas aeruginosa were isolated from patients with Urinary Tract Infection (UTI). The aim of this study was to determine the antimicrobial effect of alcoholic leaves extract of Salvia officinalis on Multidrug resistant (MDR) $P$. aeruginosa. Using the well diffusion test, the alcoholic leaves extract at $100 \mathrm{mg} / \mathrm{ml}$ and $200 \mathrm{mg} / \mathrm{ml}$ was shown to possess antimicrobial activity against the tested microorganism. The inhibition zones of $S$. officinalis at $200 \mathrm{mg} / \mathrm{ml}$, and 100 $\mathrm{mg} / \mathrm{ml}$ of the extract showed diameters of $23 \mathrm{~mm}$ and $20 \mathrm{~mm}$, respectively. But the diameters of the inhibition zones caused by treatment with the antibiotics Ciprofloxacin, Ticarcillin + Clavulanic acid, and Cefotaxime were $28 \mathrm{~mm}, 27 \mathrm{~mm}$, and $25 \mathrm{~mm}$ ) for both isolates, respectively. The results indicate that $P$. aeruginosa was resistant to most antibiotics of different groups used in this study. It was found that the isolates were Multidrug Resistant (MDR) by sensitivity test. The results of minimum inhibitory concentration (MIC), by using E-test strips, showed that MIC of Cefoxitin was $4 \mu \mathrm{g} / \mathrm{ml}$ for $P$. aeruginosa 1 , but $P$. aeruginosa 2 was resistant. MIC value for Cefoperazone was $8 \mu \mathrm{g} / \mathrm{ml}$ against $P$. aeruginosa 1 , whereas $P$. aeruginosa 2 was resistant. MIC value was also determined for the alcoholic leaves extract against $P$. aeruginosa, showing a value of $100 \mathrm{mg} / \mathrm{ml}$, while the plant extract also had synergistic effects with Ciprofloxacin, Cefotaxime, and Ticarcillin+ Clavulanic Acid. It can be concluded that the alcoholic leaves extract of $S$. officinalis had considerable antimicrobial effects on MDR P. aeruginosa. Thus, it can be used instead of antibiotics for the treatment of UTI caused by MDR $P$. aeruginosa to reduce the side effects of antibiotics. On the contrary, its use with antibiotics enhances their action without interfere with them.
\end{abstract}

Keywords: Pseudomonas aeruginosa, antimicrobial effects, Salvia officinalis, alcoholic leaves extract.

\section{التأثير الضد مايكروبي للمستخلص الكحولي لأولق Salvia officinalis ضد المالق \\ Pseudomonas aeruginosa}

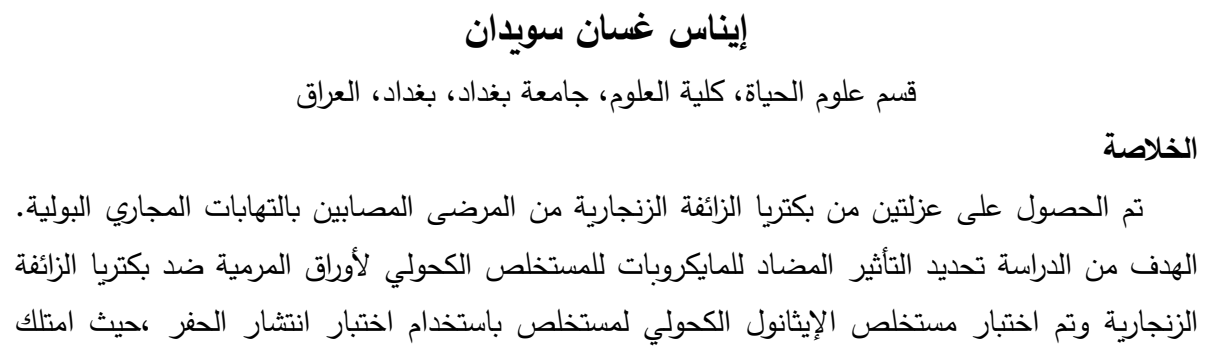




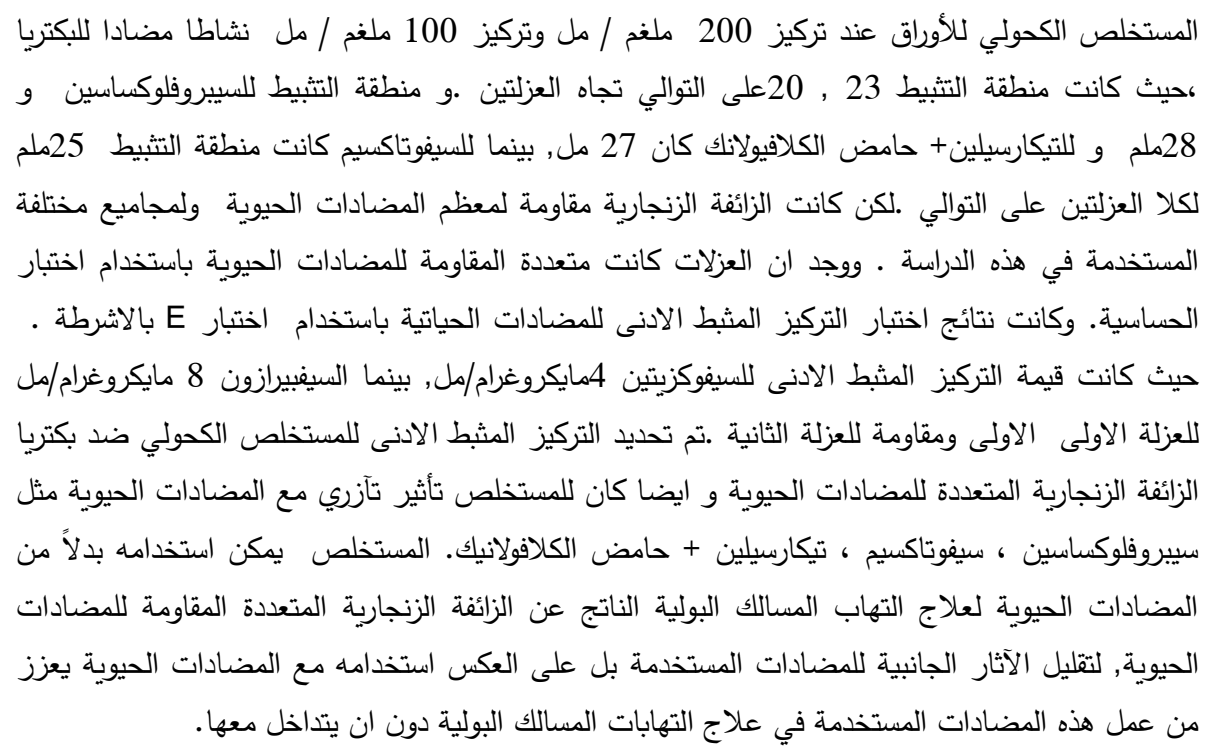

\section{Introduction:}

The effects of Pseudomonas aeruginosa are often associated with many of virulence factors secreted by this bacterium, including Pyocyanin [1]. Pyocyanin has antimicrobial activity against wide variety of micro-organisms, which may benefit $P$. aeruginosa by elimination of competing microorganisms; pyocyanin is used as an antimicrobial agent, selectively inhibiting Gram-positive and Gram-negative bacteria other than Pseudomonas spp. [2]. P. aeruginosa is resistant to high concentrations of salts and dyes, weak antiseptics, and commonly used antibiotics [3].

Pseudomonas aeruginosa is an opportunistic pathogen for humans [4]. It is not the main causing agent of UTI, but many cases may be caused by this pathogen. Pseudomonas aeruginosa is resistant to most of the antibiotics used in the treatment of UTI, especially those associated with a nosocomial infection in patients with weak immunity [5]. Plants contain many active components like alkaloids, flavonoids, steroids, and saponins such as Salvia officinalis. The pharmacological findings for Salvia officinalis include anticancer, anti-inflammatory, antinociceptive, antioxidant, antimicrobial, antimutagenic, antidementia, hypoglycemic, and hypolipidemic effects [6].

Salvia officinalis was reported to have antibacterial and antifungal effects. Phenolic acids, such as salvin and salvin monomethyl ether, excreted by this plant have antimicrobial activities, especially against Staphylococcus aureus, Pseudomonas aeruginosa and other bacteria [7]. The Aim of this study investigated the sensitivity of $P$. aeruginosa to antibiotics and determine MIC values to some antibiotics by using E-test strips. We also aimed at determining the antimicrobial activity of alcoholic leaves extract of Salvia officinalis against MDR Pseudomonas aeruginosa isolated from UTIs and estimating the synergic effects of alcoholic leaves extract of Salvia officinalis with antibiotics against MDR $P$. aeruginosa.

\section{Materials and Methods:}

\section{Isolation of Pseudomonas aeruginosa:}

The bacteria were collected from Al- Yarmouk hospital in Baghdad city. Two isolates of bacteria Pseudomonas aeruginosa were detected from patients with UTIs, by using standard methods [8]. Urine samples were cultured onto plates of MaCconkey agar, blood agar and Cetramide agar.

\section{Identification of Pseudomonas aeruginosa:}

Pseudomonas aeruginosa was identified depending on the morphological features on culture media as well as the biochemical tests described elsewhere [9], while the isolates were confirmed with VITEK 2 compact system.

\section{Preparation of alcoholic leaves extract of Salvia officinalis:}

Salavia officinalis leaves were acquired from plant stores in Baghdad. To clear dust, the leaves were washed with water and then dried in an air oven at $60 \mathrm{C}$ for 3 days. To obtain the plant powders, the air-dried plant materials were ground in a blender with a suitable size. $10 \mathrm{~g}$ of each plant powder was extracted by Soxhlet $8 \mathrm{hrs}$. with $200 \mathrm{ml}$ of $80 \%$ (v/v) aqueous ethanol. The extracts were dried in a rotary evaporator at $60^{\circ} \mathrm{C}$ and the resultant powder was kept in a closed glass container until use in refrigerator [10]. 


\section{The sensitivity test of $P$. aeruginos $a$ to antibiotics:}

The discs method was used to conduct in vitro sensitivity test according to published methodology [11]. Fifteen antibiotics discs from (Bioanalysis / Turkey) were used: Erythromycin, Clindamycin, Cefoxitin, Cephalothin, Trimethoprim, Ciprofloxacin, Imipenem/Cilactin, Cefotaxime, Ticarcillin + Clavulanic acid, Norfloxacin, Amoxicillin + Clavulanic acid, Ticarcillin, Cephalexin, Amikacin, and Imipenem. Bacteria were grown for 18 hours in Mueller Hinton broth at $37^{\circ} \mathrm{C}$ and then inoculum was placed on the media by sterile swabs after dilution to no. $0.5 \mathrm{McF}$ arland criteria $\left(1 \times 10^{8}\right.$ cell $\left./ \mathrm{ml}\right)$. The cultures and antibiotic discs were incubated to overnight incubation at $37^{\circ} \mathrm{C}$. The findings were compared with the CLIS (Clinical and Laboratory Standards Institute) data [12].

\section{MIC determination of Pseudomonas aeruginosa by E-test:}

Five antibiotic strips of E-test were used, namely those for Cefoperazone (CFP), Cefoxitin (FOX), Cefotaxime/ Cefotaxime+Clavulanic acid (CTX/CTX+), Gentamicin (HLG), and Levofloxacillin (LEV), which were obtained from (Bioanalysis/Turkey). The antibiotic sensitivity test of the clinical isolates was achieved as previously reported [10]. The bacteria were grown in Mueller Hinton broth for $18 \mathrm{hrs}$. at $37^{\circ} \mathrm{C}$, and then inoculums were placed on Mueller Hinton agar by sterile swabs after dilution to McFarland no.0.5 tube. Then, the antibiotic strips were placed on media, pressed, and then incubated at $37 \mathrm{oC}$ overnight. The results were compared with CLSI data [12].

Antibacterial activity of alcoholic leaves extract of Salavia officinalis:

The antimicrobial activity of Salavia officinalis ethanol leave extracts was tested by previously described methods $[13,14]$ by using Mueller Hinton Agar with wells method. Previously prepared, $P$. aeruginosa bacterial suspensions (with turbidity of no. $0.5 \mathrm{McFarland}$ criteria for the dilution of $1 \mathrm{x}$ $10^{8}$ cell $/ \mathrm{ml}$ ) were spread on the agar surface. Wells with diameter of $0.5 \mathrm{~cm}$ were created on agar plates by sterile cork-borer. The extract was prepared at concentrations $200,100,50,25,12.5$, and $6.25 \mathrm{mg} / \mathrm{ml}$. After loaded the wells with concentrations of extract, the plates were incubated overnight and the antibacterial activity was evaluated by the millimeter measurement of the diameter of the inhibition zones around wells. The inhibition zones were assumed to indicate the effects of the MIC of the leaves extract against (MDR) Pseudomonas aeruginosa [12] as compared to control.

Determination of the synergetic effects of Salvia officinalis and antibiotics:

To determine the synergistic effects of alcoholic leaves extract with three antibiotic discs (Ciprofloxacin $(5 \mathrm{mg})$, Cefotaxime $(30 \mathrm{mg})$, Ticarcillin + Clavulanic acid (10/10 mg)), the MIC concentration of leaves extract was added to the antibiotic discs. After that, the plates were incubated overnight. Then, a comparison was made between the regions of inhibition of antibiotic discs alone with those of antibiotic discs with alcoholic leaves extract, to observe the synergistic effects of alcoholic leaves extracts with antibiotics. The test was performed at the same conditions as previously described [15].

\section{Results and discussion:}

Isolation and identification of Pseudomonas aeruginosa:

Thirty urine samples were collected and cultured on MacConkey agar, blood agar. But only two isolates were belonged to Pseudomonas aeruginosa. The isolates are gram negative bacteria appeared as pale colonies. On blood agar, the beta type of haemolysis was observed, while $P$. aeruginosa isolates were positive for the oxidase test. Many strains of $P$. aeruginosa produce various species of pyocyanin on Cetramide agar [8]. The result shown in Table-1 indicate that these tests identified only two isolates belonging to Pseudomonas aeruginosa, and the detection was confirmed by VITEK 2 System.

Table 1-The results of Cultural and Morphological tests of $P$. aeruginosa:

\begin{tabular}{|c|c|}
\hline The test name & Results \\
\hline Microscopically & Gram negative \\
\hline MacConkey agar & Pale colonies \\
\hline Blood agar & Beta haemolysis \\
\hline Cetramide agar & Pyocynin pigment production \\
\hline oxidase & positive \\
\hline
\end{tabular}




\section{The sensitivity test of $P$. aeruginos $a$ to antibiotics:}

The sensitivity test of two isolates ( $P$. aeruginosa 1 and $P$. aeruginosa 2 ) isolated from UTI patients was conducted against fifteen antibiotic discs. The results of sensitivity to Ciprofloxacin showed that the inhibition diameter is $28 \mathrm{~mm}$ for $P$. aeruginosa 1 and $25 \mathrm{~mm}$ for P. aeruginosa 2 . Both isolates of $P$. aeruginosa were showed inhibition zone in the diameter of $25 \mathrm{~mm}$ in response to Cefotaxime. $P$. aeruginosa 1 was sensitive to Imipenem/Cilactin with a diameter of $27 \mathrm{~mm}$, while $P$. aeruginosa 2 showed a diameter of $11 \mathrm{~mm}$, indicating resistance. It was also found that the two isolates were sensitive to Ticarcillin + Clavulanic Acid with inhibition zone diameter of $27 \mathrm{~mm}$ (Table-2). This agrees whit the results of another study which reported that that $P$. aeruginosa isolates, especially those isolated from UTI are resistant to high concentrations of salts and dyes, weak antiseptics, and commonly used antibiotics [16]. P. aeruginosa showed the highest resistance rate to Erythromycin, Clindamycin, Cefoxitin, Cephalothin, and Trimethoprim, while the lowest resistance rate was to Ticarcillin, and Imipenem, respectively, according to the antibiotic sensitivity test. Also, the highest sensitivity rate was observed against the antibiotics Ciprofloxacillin, Cefotaxime, Ticarcillin + Clavulanic Acid for both isolates. In a previous study, P. aeruginosa isolated from the eyes showed resistance to Cephalothin, Ofloxacin, Piperacillin, and Moxifloxacin, but was sensitive to Chloramphenicol and Ciprofloxacin [17]. In another report of sensitivity test, Imipenem and Gentamicin showed antimicrobial effects on gram positive bacteria, while Imipenem was more effective against gram positive bacteria [15]. The isolates in this study were resistant to different groups of antibiotics more than four groups. Therefore, these isolates were identified as MDR $P$. aeruginosa, as described in CLSI instructions [11]. Other studies have specifically reported on patients with infection caused by MDR P. aeruginosa. However, as the resistance to many of these antibiotics increases, it becomes imperative that more antibiotics be discovered as an effective treatment for infections caused by MDR P. aeruginosa. [18].

Table 2-The results of sensitivity test to antibiotics against $P$. aeruginosa:

\begin{tabular}{|c|c|c|c|}
\hline ID & Antibiotic & P. aeruginosa 1 & P.aeruginosa 2 \\
\hline 1 & Cephalothin & $0 \mathrm{~mm}(\mathbf{R})$ & $0 \mathrm{~mm}(\mathbf{R})$ \\
\hline 2 & Clindamycin & $0 \mathrm{~mm}(\mathbf{R})$ & $0 \mathrm{~mm}(\mathbf{R})$ \\
\hline 3 & Cefalexin & $9 \mathrm{~mm}(\mathbf{R})$ & $10 \mathrm{~mm}(\mathbf{R})$ \\
\hline 4 & Amikacin & $18 \mathrm{~mm}(\mathbf{R})$ & $17 \mathbf{m m}(\mathbf{R})$ \\
\hline 5 & Ciprofloxacin & $28 \mathrm{~mm}(\mathbf{S})$ & $28 \mathrm{~mm}(\mathbf{S})$ \\
\hline 6 & Erythromycin & $0 \mathrm{~mm}(\mathbf{R})$ & $0 \mathrm{~mm}(\mathbf{R})$ \\
\hline 7 & Norfloxacin & $19 \mathrm{~mm}(\mathbf{R})$ & $20 \mathrm{~mm}(\mathbf{R})$ \\
\hline 8 & Amoxicillin + Clavulanic Acid & $13 \mathrm{~mm}(\mathbf{R})$ & $12 \mathrm{~mm}(\mathbf{R})$ \\
\hline 9 & Cefotaxime & $25 \mathrm{~mm}(\mathbf{S})$ & $25 \mathrm{~mm}(\mathbf{S})$ \\
\hline 10 & Ticarcillin + Clavulanic Acid & $27 \mathrm{~mm}(\mathbf{S})$ & $27 \mathrm{~mm}(\mathbf{S})$ \\
\hline 11 & Cefoxitin & $0 \mathrm{~mm}(\mathbf{R})$ & $0 \mathrm{~mm}(\mathbf{R})$ \\
\hline 12 & Trimethoprim & $0 \mathrm{~mm}(\mathbf{R})$ & $29 \mathrm{~mm}(\mathbf{S})$ \\
\hline 13 & Imipenem/Cilactin & $27 \mathrm{~mm}(\mathbf{S})$ & $11 \mathrm{~mm}(\mathbf{R})$ \\
\hline 14 & Ticarcillin & $13 \mathrm{~mm}(\mathbf{R})$ & $11 \mathrm{~mm}(\mathbf{R})$ \\
\hline 15 & Imipenem & $10 \mathrm{~mm}(\mathbf{R})$ & $5 \mathrm{~mm}(\mathbf{R})$ \\
\hline & & & \\
\hline
\end{tabular}




\section{MIC determination of Pseudomonas aeruginosa by E-test:}

The E-test by diffusion method was used to evaluate the MIC. The results showed elliptical inhibition zones around the strips, as in Figure-1 and Table-3. In this study, Cefoxitin and Cefoperazone , Levofloxacin strips were used for two isolates of $\mathrm{P}$. aeruginosa, and they were giving MIC values $(4,8,6 \mu \mathrm{g} / \mathrm{ml}$, respectively) only for the isolate of P. aeruginosa 1; whereas P. aeruginosa 2 did not show inhibition for these antibiotic strips. Gentamicin showed MIC values of 6 and $4 \mu \mathrm{g} / \mathrm{ml}$ for both isolates respectively. MIC Strip is a rapid and reliable method for determining the antimicrobial susceptibility of different microorganisms against antibiotics. The E-test for Cefotaxime/Cefotaxime + Clavulanic acid was also used to determine ESBLs (Extended spectrum beta-lactamases) production by P. aeruginosa. According to CLSI results, when the MIC value of Cefotaxime/Cefotaxime + Clavulanic acid was lower than 8, this indicated that the isolate is resistant to these antibiotics [11].And these isolates were ESBLs producers.

Table 3-The results of E-test antibiotic strips against MDR P. aeruginosa:

\begin{tabular}{|c|c|c|}
\hline $\begin{array}{c}\text { Names of E-test antibiotic } \\
\text { strips }\end{array}$ & $\begin{array}{c}\text { MIC of P. aeruginosa } 1 \text { in } \\
\mu \mathrm{g} / \mathrm{ml}\end{array}$ & $\begin{array}{c}\text { MIC of P. aeruginosa 2 in } \\
\mu \mathrm{g} / \mathrm{ml}\end{array}$ \\
\hline Cefoxitin & 4 & $\mathrm{R}$ \\
\hline Cefoperazone & 8 & $\mathrm{R}$ \\
\hline Cefotaxime/ Cefotaxime + & $1.5 / 0.16$ & $0.32 / 2$ \\
\hline Gentamycin & 6 & 4 \\
\hline Levofloxacin & 6 & $\mathrm{R}$ \\
\hline
\end{tabular}

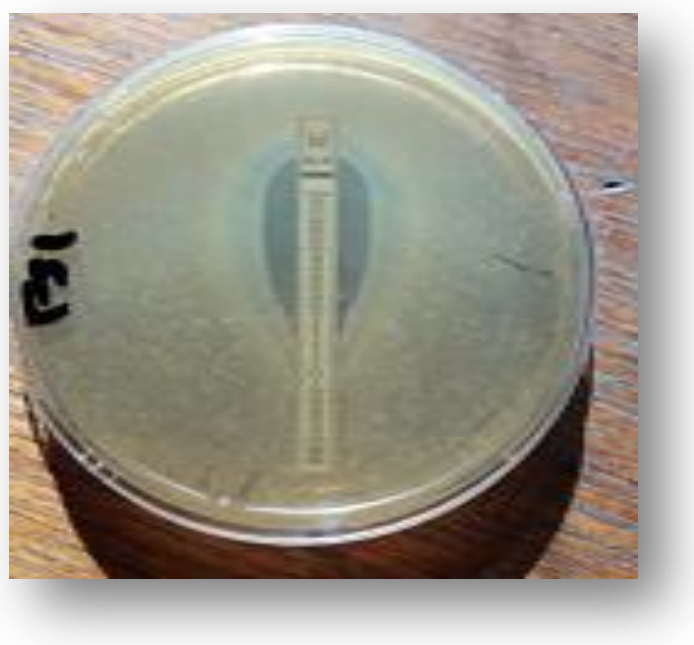

A

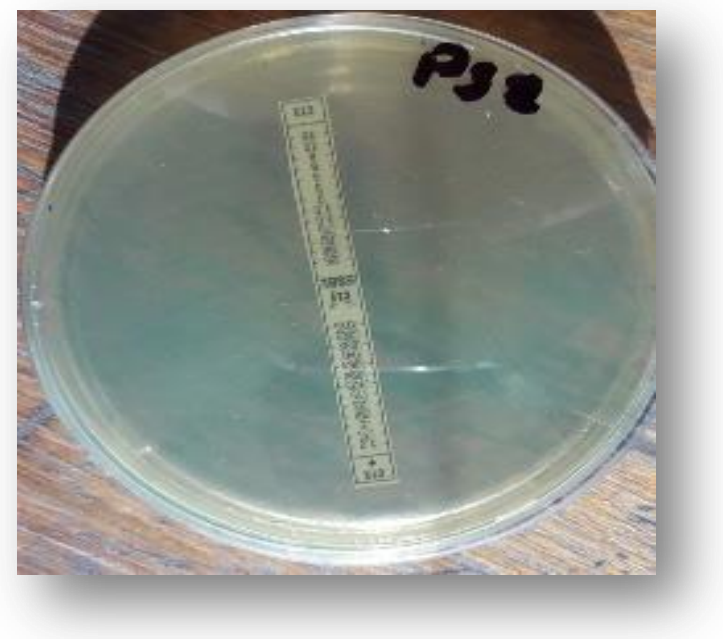

B

Figure 1-E-test strips of antibiotics against MDR P. aeruginosa. A: Gentamycin E-test strip; B: Cefotaxime/ Cefotaxime + E-test strip

\section{Antibacterial activity of alcoholic leaves extract of Salvia officinalis:}

The data showed a clear inhibitory effect of Salvia officinalis leaves extract at concentrations of $200 \mathrm{~m}$ $\mathrm{g} / \mathrm{ml}$ was $(23 \mathrm{~mm})$ but, in $100 \mathrm{mg} / \mathrm{ml}$ concentration was $(20 \mathrm{~mm})$, while the other concentrations showed no inhibitory activity against both $P$. aeruginosa isolates. These results agree with those reported by another study which found that the plant has antibacterial activity against $P$. aeruginosa $[13,14]$. Other herbal plants, such as methanolic alcohol extract and fractions of $C$. longa 
L. rhizomes, C. myrrha L. gums showed biological activities against P. aeruginosa and S. aureus [19]. The results of this study agree with another study which found that the flavonoids of $S$. officinalis had antibacterial activities against $S$. aureus and $P$. aeruginosa [20]. The MIC value of $S$. officinalis was $100 \mathrm{mg} / \mathrm{ml}$ against $P$. aeruginosa, but the results of Muttalib and Naqishbandi were found that of $75 \%$ S. officinalis alcoholic leaves extract in $100 \mathrm{mg} / \mathrm{ml}$ concentration did not exert activity against $P$. aeruginosa [21].

Comparing inhibitory activity of antibiotic discs and plant extracts of $S$. officinalis against MDR P. aeruginosa:

As observed in Figure-2, alcoholic leaves extract of S. officinalis at a concentration of $200 \mathrm{mg} / \mathrm{ml}$, and $100 \mathrm{mg} / \mathrm{ml}$ had an inhibition zones diameter $23 \mathrm{~mm}, 20 \mathrm{~mm}$ respectively. These results demonstrate more potent inhibition activity as compared to those of antibiotics as Erythromycin $(10 \mu \mathrm{g} / \mathrm{ml})$ and Cephalothin $(30 \mu \mathrm{g} / \mathrm{ml})$, against $P$. aeruginosa. However, the inhibition zone value was less than that caused by Ciprofloxacin and close to those caused by Cefotaxime. These results indicate the possibility of the use of S. officinalis leaves extract to treat UTIs caused by MDR P. aeruginosa instead of using antibiotics, especially that the plants extracts have less side effects than those caused by antibiotics. The $S$. officinalis extract was found to have antibacterial activities against $P$. aeruginosa with the ability of preventing biofilm formation also [22].

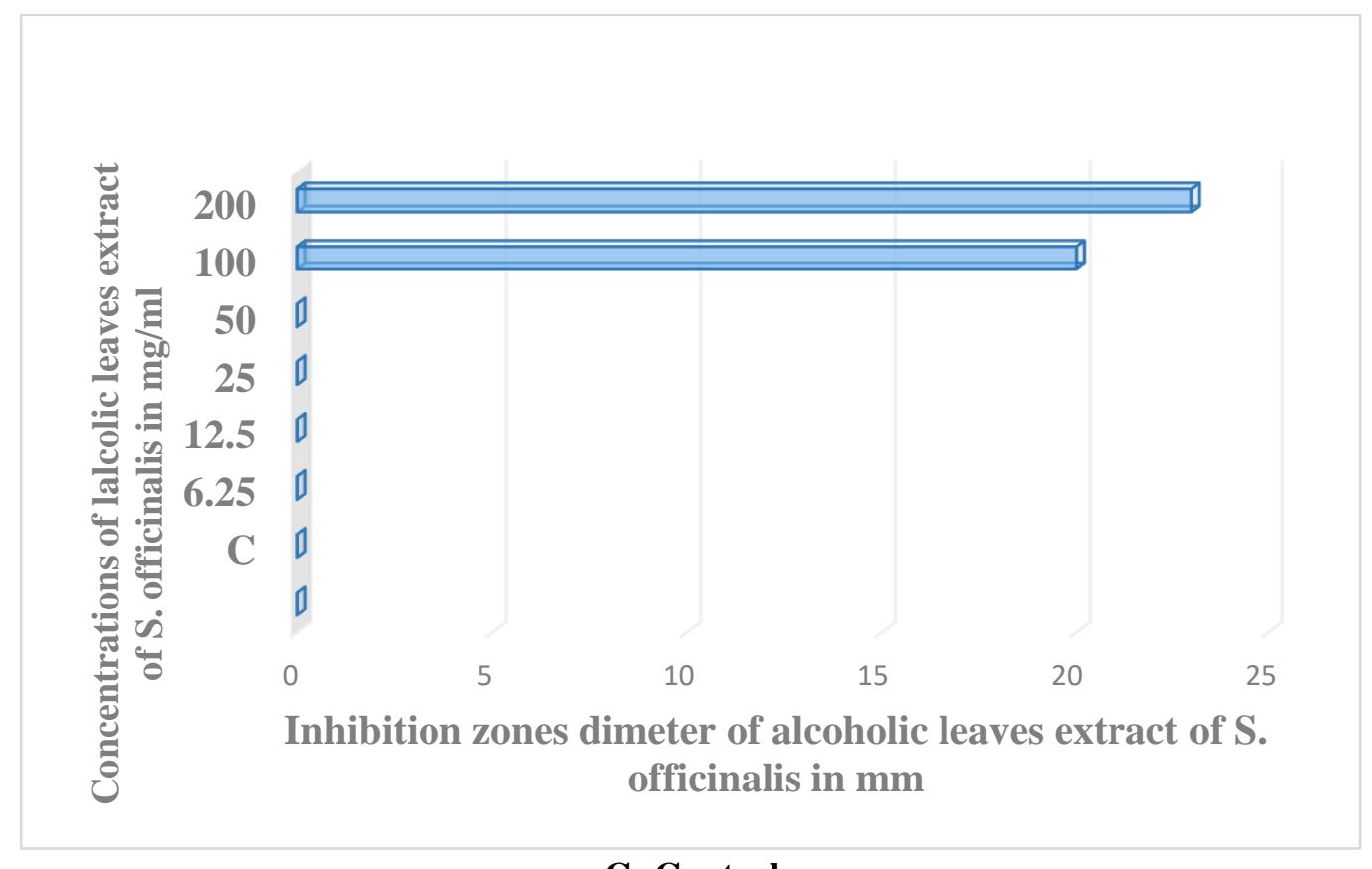

\section{C: Control}

Figure 2-The inhibitory activity of alcoholic leaves extract of Salvia officinalis against MDR $P$. aeruginosa.

\section{Determination of the synergetic effects of alcoholic leaves extract of Salvia officinalis with antibiotics:}

After adding the MIC concentration of alcoholic leaves extract to antibiotic discs, the results were presented in Table-4. Only the antibiotics which showed sensitivity effects against the bacteria were then added to MIC concentrations of the plant extract. The results showed an increased inhibition zones of antibiotic discs with added to plant extract, while the inhibition zones of antibiotics without plant extract were smaller. Other studies showed synergistic interactions between amoxicillin and acetone or ethyl acetate extract of Salvia officinalis and between chloramphenicol and ethyl acetate extract of Salvia officinalis against Pseudomonas aeruginosa, Staphylococcus aureus, Bacillus subtilis, Enterobacter cloacae, and Klebsiella pneumoniae. But the same study excluded that alcoholic plant extract of Salvia officinalis can initiate the activity of antibiotics against the resistant bacteria, such as Pseudomonas aeruginosa, when used in combination with antibiotics [23], however 
this study's result which showed that alcoholic leaves extract Salvia officinalis has synergetic effects when used with antibiotics such as (Ciprofloxacin, Cefotaxime, Ticarcillin + Clavulanic Acid).

Table 4-The synergetic effects of alcoholic leaves extract of Salvia officinalis with antibiotic discs against MDR Pseudomonas aeruginosa:

\begin{tabular}{|c|c|c|}
\hline Antibiotics discs & $\begin{array}{c}\text { The diameter of inhibition zone } \\
\text { of antibiotic discs without } S . \\
\text { officinalis }\end{array}$ & $\begin{array}{c}\text { The diameter of inhibition } \\
\text { zone of antibiotic discs with } S . \\
\text { officinalis }\end{array}$ \\
\hline Ciprofloxacin & $28 \mathrm{~mm}$ & $30 \mathrm{~mm}$ \\
\hline $\begin{array}{c}\text { Cefoxtaxime } \\
\text { Ticarcillin+Clavulanic } \\
\text { Acid }\end{array}$ & $25 \mathrm{~mm}$ & $33 \mathrm{~mm}$ \\
\hline
\end{tabular}

In this study, we can conclude that alcoholic leaves extract of $S$. officinalis had antimicrobial effects on MDR $P$. aeruginosa that were similar to those caused by antibiotics. Therefore, it is important to replace antimicrobial therapy (antibiotics) by treatment with plant extracts or pharmaceutical preparations. The latter can cause an effective elimination of MDR $P$. aeruginosa, whereas the repeated use of antibiotics stimulates the emergence of new strains of resistant pathogenic bacteria. The side effects of plants are less than those of chemotherapeutic agents, especially when taking into account the proof that concentrations less than $300 \mu \mathrm{g} / \mathrm{ml}$ of $S$. officinalis leaves extract had not cause injury on the cell membrane solidity and maintenance [24].

\section{References}

1. Mavrodi, D. V. and Thomashow, L. S. 2001. Functional analysis of Genes of Biosynthesis of Pyocyanin and phenazine-1- carboximide from Pseudomonas aeruginosa PA01. J. Bacteriology. 21: 6454-6465.

2. Sweedan Enass G. 2010. Study the effect of Antibiotics on pyocyanin production from Pseudomonas aeruginosa and pyocyanin as Antibiotic against different pathogenic bacteria". J. of university of Anbar for pure science; 4(1): 4-9

3. Todar, Kenneth: Todar, S. 2004. Textbook of Bacteriology. "The Good, the Bad, and the Deadly". (SCIENCE Magazine - June 4, - Vol 304: p 1421.

4. Vianelli, N.; Giannini, M.B. \& Quartic, C. 2006. Resolution of a Pseudomonas aeruginosa outbreak in a haematology unit with the use of disposable sterile water filter. Haematol J.; 91 (7): $983-985$.

5. Orenstein, R. and Wong, E. S. 1999. Urinary tract infections in adults. American Family Physician; www. aafp.org /afp/99031ap /1225.html.

6. Acar, J.F. and Rostel, B. 2001. Antimicrobial resistance: an overview. Rev. Sci. tech. Off. Int. Epiz., 20(3): 797 - 810.

7. Ahmad Ghorbani and Mahdi Esmaeilizadeh. 2017. Pharmacological properties of Salvia officinalis and its components. Journal of Traditional and Complementary Medicine. 7(4): 433440

8. Edwin, L.; Dimatatac, M.D.; Marissa, M.; Alejandria, M.D.; Cecilia Montalban; M.D.; Cristina Pineda, R.M.T.; Concepcion Ang, R.M.T. \& Rachel Delino, M.S. 2003. Clinical Outcomes and Costs of Care of Antibiotic Resistant Pseudomonas aeruginosa infections. Phil. J. Microbiol. Infect. Dis.; 32(4): 159 - 167.

9. Collee, J. G., Miles, R. S. and Watt, B. 1996. Test for the identification of bacteria. In: Collee. J. G.; Fraser, A. G.; Marmion, B. P. and Simmons, A. (Eds). Practical Medical Microbiology. 14P th Edition. Churchill Livingstone, New York. pp. 131-146.

10. Ahmed, I., Mehmood, Z. and Mohammad, F. 1998. Screening of some Indian medicinal plants for their antimicrobial properties J. Enthnopharmacole., 62: 183 - 193. 
11. Bauer, A.W., Kirby, WMM, Sherhis, JC. and Turck, M. 1966. Antibiotic susceptibility testing by a standardized single disc method. Amer. J. Clin. Path. ,45: 493-496

12. Clinical and L.S. 2017. Institute, M100-S25 Performance Standards for Antimicrobial Susceptibility Testing; Twenty-Fifth Informational Supplement. CLSI, 35: 1-240.

13. Das, K., Tiwari, R.K.S. and Shrivastava, D.K. 2010. Techniques for evaluation of medicinal plant products as antimicrobial agent: Current methods and future trends. J. Med. Plant. Res., 4(2):104111.

14. Davut karaasian; and Mensure Özgüven. 2001. Determination of qualitative and quantitative of Sage (Salvia officinalis L.) essential oils. Pakistan journal of Biological Science; 4(1): 41-43.

15. Jinan M. Hasan, and Alaa M. Dh. Al-Haidari.2015. The Antimicrobial Effect of Alcoholic Extract of Peganum harmala L Seeds on Clinically Isolated Gram Negative and Gram Positive Bacteria. Iraqi Journal of Science; 56(2C): 1653-1660.

16. H.Ali Salih M. Abdulbary A.S. Abdulrida . 2011. Susceptibility of Pseudomonas aeruginosa isolated from urine to some antibiotics. AL-Qadisiya Journal of Vet.Med.Sci.; 10(2): 86-89.

17. May T. Flayyih, Enass G. Sweedan, Luma S. Mohammed.2012. Study The Effect Of Some Inhibitor Factors On Production Of Some Virulence Factors Of Pseudomonas Aeruginosa And Their Ability For Adhesion To Contact Lenses. Iraqi Journal of Science; 53(1): 25-29.

18. Tunde Jurca, Ioana Baldea, Gabriela Adriana Filip, Diana Olteanu, Simona Clichici, Annamaria Pallag, Laura Vicaş, Eleonora Marian, Otilia Micle , Carmen Bianca Crivii, and Mariana Mureşan.2020. A Phytocomplex Consisting of Tropaeolum majus L. and Salvia officinalis $L$. Extracts Alleviates the Inflammatory Response of Dermal Fibroblasts to Bacterial Lipopolysaccharides. Oxidative Medicine and Cellular Longevity; Volume 2020, Article ID 8516153, 14 pages.

19. Meison Abdulbary, Ahmed Abies Motar and Rajaa Ali Hussein.2018. Antibacterial Effect of Some Medicinal Plants against Staphylococcus aureus and Pseudomonas aeruginosa. International Journal for Research in Applied Sciences and Biotechnology. 5(4): 8-14.

20. Lynn Nguyen, Joshua Garcia, Katherine Gruenberg, Conan MacDougall.2018. MultidrugResistant Pseudomonas Infections: Hard to Treat, But Hope on the Horizon? Curr. Infect. Dis. Rep.; 20(8): 23.

21. Lana Y. Muttalib and Alaadin M. Naqishbandi. 2012. Antibacterial and Phytochemical Study of Iraqi Salvia officinalis Leave Extracts. Iraqi J. Pharm. Sci.; 21(1): 93-97.

22. Yassir Lekbachab, Zhong Lia ,Dake Xu ,Soumya El Abed, Dan Liu, Tingyue Gu ,Saad Ibn souda Koraichib ,Ke Yang,Fuhui Wang. 2019. Salvia officinalis extract mitigates the microbiologically influenced corrosion of 304L stainless steel by Pseudomonas aeruginosa biofilm. Bioelectrochemistry; 128: 193-203

23. Olgica D. Stefanovi, Dragana D. Stanojevi And Ljiljana R.2012 Synergistic Antibacterial Activity Of Salvia Officinalis And Cichorium Intybus Extracts And Antibiotics. Acta Poloniae Pharmaceutica - Drug Research; 69(3): 457-463

24. Saha R., Roychodhury S., Kar K., Varghese Ac., Nandi P., Sharma Gd., Formicki G., Slama P. and Kolesarova A. 2019. Coenzyme Q10 ameliorates cadmium induced reproductive toxicity in male rats. Physiological Research; 68: 141-145. 